\title{
Article
}

\section{Creative analogy use in a heterogeneous design team: The pervasive role of background domain knowledge}

Christensen, BT and Ball, Linden

Available at http://clok.uclan.ac.uk/15602/

Christensen, BT and Ball, Linden ORCID: 0000-0002-5099-0124 (2016)

Creative analogy use in a heterogeneous design team: The pervasive role of background domain knowledge. Design Studies, 46 . pp. 38-58. ISSN $0142694 X$

It is advisable to refer to the publisher's version if you intend to cite from the work. http://dx.doi.org/10.1016/j.destud.2016.07.004

For more information about UCLan's research in this area go to http://www.uclan.ac.uk/researchgroups/ and search for < name of research Group>.

For information about Research generally at UCLan please go to http://www.uclan.ac.uk/research/

All outputs in CLoK are protected by Intellectual Property Rights law, including Copyright law. Copyright, IPR and Moral Rights for the works on this site are retained by the individual authors and/or other copyright owners. Terms and conditions for use of this material are defined in the policies page.

\section{CLoK}

Central Lancashire online Knowledge www.clok.uclan.ac.uk

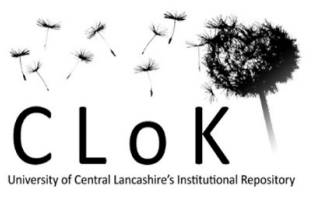


Authors' Accepted Manuscript. The copyedited article may differ from this version. The details of the published article are as follows:

Christensen, B. T., \& Ball, L. J. (in press). Creative analogy use in a heterogeneous design team: The pervasive role of background domain knowledge. Design Studies.

Creative Analogy Use in a Heterogeneous Design Team: The Pervasive Role of Background Domain Knowledge

SHORT TITLE: Creative Analogy Use in a Heterogeneous Design Team

\section{Bo T. Christensen*}

Department of Marketing

Copenhagen Business School, Copenhagen, Denmark

\section{Linden J. Ball}

School of Psychology

University of Central Lancashire, Preston, UK

\footnotetext{
*Corresponding Author:

Bo T. Christensen

Copenhagen Business School, Department of Marketing

Solbjerg Plads 3, 2000 Frederiksberg C

Denmark

Email: bc.marktg@cbs.dk

Tel: +4538152123

Abstract
} 
We integrated two research traditions - one focusing on analogical reasoning, the other on knowledge sharing - with the aim of examining how designers' unique knowledge backgrounds can fuel analogy-based creativity. The present dataset afforded a unique opportunity to pursue this aim since the design dialogue derived from team members with highly disparate educational backgrounds. Our analyses revealed that analogies that matched (versus mismatched) educational backgrounds were generated and revisited more frequently, presumably because they were more accessible. Matching analogies were also associated with increased epistemic uncertainty, perhaps because domain experts appreciate the challenge of mapping such analogies between domains. Our findings support claims from the knowledge-sharing literature for a direct route from knowledge diversity through analogical reasoning to novel idea production.

\section{Keywords}

Design cognition, analogical reasoning, creative design, collaborative design, conceptual design 
The design process typically involves designers drawing on personal experiences relating to their past design work as well as on knowledge of other design projects or products (e.g., Ball, Lambell, Reed, \& Reid, 2001; Cross, 2006). Such prior experience and knowledge then serves to inform a solution for the current design problem, shaping both its initial development and its subsequent refinement. Indeed, the very notion of 'design-by-analogy' (e.g., Helms, Vattam, \& Goel, 2009; Moreno et al., 2014) points specifically to the frequent capacity for designers to transfer solution structures or elements from a known source domain to a target design problem.

In studying such design-by-analogy, researchers have often tended - perhaps inadvertently - to control out individual variation in the background domain knowledge of the designers being analysed, instead focusing on homogeneous participants with very similar backgrounds in terms of their design education, training and company-based experiences, for example, in domains such as industrial product design (e.g., Ball, Ormerod, \& Morley, 2004), electronic engineering design (e.g., Jagodzinski, Reid, Culverhouse, Parsons, \& Phillips, 2000) or the design of medical plastics (e.g., Christensen \& Schunn, 2007). In the extreme case of numerous laboratory experiments that have investigated design-by-analogy the source analogies are presented directly to individual participants in the form of one or more initial examples for perusal (e.g., Casakin, 2004; Casakin \& Goldschmidt, 1999; Goldschmidt, 1995). In this way very tight constraints are placed on the experimental setting so that the researcher can assess the specific role that such source materials have on the design process and the resulting design products.

These latter kinds of laboratory studies are actually rather paradoxical, since although it is assumed that analogy sources in real-world design practice are frequently drawn from a designer's own background knowledge and experience, the examination of analogy use in highly controlled experimental situations does not readily allow for an investigation of the way in which individual 
variation between designers makes a difference to the analogies that are retrieved and the design solutions that are produced. We contend, however, that the role of individual variation in background knowledge is vitally important for attaining a full understanding of the basis of design creativity and innovation. This view is supported by established research on 'knowledge sharing' in teams (e.g., Cummings, 2004; Pulakos, Dorsey, \& Borman, 2003), which is often concerned with examining the nature of individual differences in knowledge backgrounds in order to estimate the impact of such differences on outcome measures such as creativity and innovation. In such research the exchange of previously unshared knowledge in heterogeneous or multifunctional teams and organizations is often observed to be beneficial (e.g., Argote, 1999, Nonaka, 1994).

What is fascinating about the separate research traditions that focus on design-by-analogy on the one hand and knowledge sharing in team creativity on the other hand is that they both seem intuitively to be closely connected in terms of their concern with the application of prior knowledge to new problems. Indeed, on reflection, it is apparent that both traditions seem to assume that the central path by which background domain knowledge may be transferred into innovative outputs is through a process of analogical reasoning. Yet achieving a theoretical rapprochement between these two disparate traditions is far from straightforward because of their methodological differences. As we have noted, experimentally-driven, design-by-analogy research typically aims to hold background knowledge constant either by utilizing homogeneous design participants or else by presenting source analogies that are equally available to each participant in the experimental context, thereby making it unclear whether individual variation in background domain knowledge makes any difference at all to the analogizing process. In contrast, the knowledge-sharing literature capitalizes fully upon individual differences in the knowledge and backgrounds of members of heterogeneous teams so as to examine how such differences translate into outcomes of interest such as team conflict, intent to remain in team or team performance. Furthermore, studies of knowledge- 
sharing examine knowledge transfer at the aggregate, team level as opposed to at the level of individual participants, thus making it in unclear whether enhancements that are observed in team innovation are caused by analogical reasoning or by some other aspect of team activity. In other words, the knowledge-sharing literature really only demonstrates that a 'potential' for creativity exists in the exchange and integration of previously unshared domain knowledge within heterogeneous teams (e.g., Argote, 1999, Nonaka, 1994), rather than establishing decisively that innovation arises specifically through a process of analogizing.

Unlike many previous studies of analogizing in design, the dataset that was examined in the present research provided a rare opportunity to examine analogy use specifically through the lens of individual differences in background domain knowledge. This is because the study that gave rise to the dataset involved design students from diverse educational disciplines, thereby making it possible to analyse whether the analogies being invoked stemmed from the unique domain knowledge of particular individuals. Furthermore, the nature of the dataset also made it possible to examine whether analogies that derived from a particular designer's domain background were qualitatively different from ones that did not derive from their domain background.

Notwithstanding the fact that the present dataset goes some way toward amalgamating two distinct research traditions within a single study, the dataset nevertheless provided some methodological challenges for the present analysis given that a large number of uncontrollable factors were inscribed into the fabric of the study. For this reason, the present analysis should be seen as a first, small-scale attempt to look specifically at how differences in background domain knowledge may influence analogical reasoning processes. We endeavored to explore this question utilising the quasi-experimental setup afforded through the study, including available information on the educational background of the participants. Before we summarise the hypotheses that we generated 
to inform our data analysis we first review the literatures on analogical reasoning in design and on knowledge sharing in design so as to justify the basis of our hypotheses.

\section{Analogical reasoning}

Analogical reasoning involves accessing and transferring previously acquired knowledge of objects, attributes and relations in order to support current problem-solving and decision-making activities, making this process central to intelligent thought and creative cognition (e.g., Gentner \& Stevens, 1983; Holyoak \& Thagard, 1997) as well as to innovative design and product development (e.g., Ball \& Christensen, 2009; Ball et al., 2004; Casakin, 2004; Casakin \& Goldschmidt, 1999; Christensen \& Schunn, 2007; Moreno et al., 2014; Visser, 1996). The key process of analogising involves transferring structural information from a source domain to a target problem. The conceptual 'distance' between the source and the target may be large or small, involving varying degrees of superficial similarity to supplement the more abstract structural similarity that is the prerequisite for structural mapping and knowledge transfer. A conceptual distance transferring information from a source to a target in the same domain is typically called a 'within-domain' analogy, whereas transferring across domain boundaries is called a 'between-domain' analogy. Both types of analogical distance have been found to be important in design and arise frequently during the design process (Christensen \& Schunn, 2007).

The experimental literature on analogy has found that superficially similar source and target problems facilitate analogical retrieval (Gick \& Holyoak, 1980; Holyoak \& Koh, 1983; see also Bearman, Ball \& Ormerod, 2007, for corroboratory evidence from real-world research). Ward (e.g., 1994, 1995, 1998) has proposed a 'path-of-least-resistance' (POLR) model to explain this observation, stating that the default approach in tasks involving the imagination, especially when few constraints must be satisfied, is to access a specific known entity or category exemplar and 
subsequently to pattern the new entity after it. There is, however, a downside to taking the path of least resistance, since it has been found that people who fixate on specific exemplars are less original in their idea productions than people who use other strategies (e.g., Christiaans \& Andel, 1993; Dahl \& Moreau, 2002; Jansson \& Smith, 1991; Ward, Patterson, Sifonis, Dodds, \& Saunders, 2002).

This latter research on phenomena such as 'design fixation' and 'exemplar influence' in generative tasks supports the notion that having or making examples available will bias people's creations toward features that are present in those examples. Furthermore, as also predicted by the POLR model, it has been shown that stimulus categories compete for designers' attention, and that withindomain products not only attract the most attention but are also considered to be the most inspirational to designers (Christensen, 2010; Christensen \& Schunn, 2009). While these POLR studies control experimentally for the accessibility of analogies, the POLR theory would nevertheless predict that source analogies from a designer's own educational domain should be more accessible or 'available' (e.g., Reber, 2004) than those from outside of their educational domain.

Anecdotal claims regarding the creative potential for analogies in problem solving often refer to the capacity for between-domain analogies to fuel innovative leaps within a conceptual space.

However, this supposed close link between distant analogies and conceptual leaps has recently been questioned (Chan \& Schunn, 2015; Chan, Dow, \& Schunn, 2015), suggesting instead that any analogy involves creative potential. While most of the design-by-analogy literature focuses on the problem solving potential of analogies, analogies also serve other functions in actual design practice. Christensen and Schunn (2007), for example, found that analogies also served the functions of problem identification and explanation (for the benefit of other designers), and Ball and 
Christensen (2009) supplemented this categorization with a fourth purpose of 'finding new functions' in relation to some pre-inventive structure. Casakin, Ball, Christensen, and BadkeSchaub (2015) additionally showed that analogizing fulfils a further valuable function by engendering enhanced team cohesion and collaboration.

Analogical reasoning has been linked to higher levels of 'epistemic uncertainty', which arises when a designer implies that they lack adequate knowledge or understanding of the design problem or its solution. For example, Ball and Christensen (2009) found that analogizing in design transcripts was directly associated with an increased use of words directly expressing subjective uncertainty. Chan, Paletz, and Schunn (2012) refined this observation by showing in a time-lagged logistic regression that epistemic uncertainty in relation to problem-solving analogies increases prior to analogizing, maintains an elevated level throughout analogizing, and then subsequently returns to a baseline level just after analogizing.

A few studies examining the ability to solve problems by analogy have also looked at individual differences, mainly in terms of levels of expertise (Novick, 1988; Novick \& Holyoak, 1991), creative ability (Corkill \& Fanger, 1995) or reasoning ability and thinking style (Antonietti \& Gioletta, 1995). Antonietti and Gioletta (1995, Study 5) additionally examined whether background knowledge in the target domain (as opposed to the source domain) would facilitate problem solving. They asked students from biology and medicine versus the humanities to solve Duncker's radiation problem, the solution to which involves weak-intensity rays from multiple directions converging to destroy a stomach tumour. Antonietti and Gioletta observed that biology and medicine students were able to solve the problem more frequently, showing how familiarity with a target domain facilitates analogical transfer. Note, however, that Antonietti and Gioletta were addressing a different research question to the one that we focus on, since we are seeking to identify whether 
background knowledge with a source domain influences the chances of producing an analogy to help solve a target problem.

\section{Knowledge sharing}

Knowledge sharing in organizations refers to the provision of task information and 'know-how' for helping others and to enable collaboration to solve problems, develop new ideas, or implement policies or procedures (Cummings, 2004; Pulakos et al., 2003; Wang \& Noe, 2010). Knowledge sharing can occur through written exchanges and documentation as well as through face-to-face communications in dyads or teams (Cummings, 2004; Pulakos et al., 2003). It is face-to-face, teambased communication that is the subject of the present analysis.

It has been argued that knowledge sharing is the fundamental means through which employees can contribute to knowledge application and innovation - and ultimately to the competitive advantage of an organization (Jackson, Chuang, Harden, Jiang, \& Joseph, 2006). Individual-level knowledge sharing among employees is influenced by factors such as organizational context, interpersonal and team characteristics, cultural characteristics, individual characteristics and motivational factors (Wang \& Noe, 2010). Individual-level knowledge sharing in turn - and by necessity - influences knowledge at the team and organizational levels (e.g., Gupta \& Govindarajan, 2000; Nonaka, 1994; Polanyi, 1966). Indeed, Nonaka $(1991,1994)$ has argued that 'metaphor' may be the key trigger for organizational knowledge creation when converting tacit knowledge into explicit knowledge, whilst analogy is claimed to be the next, more structured, intermediate step between intuition and logical thinking, resulting finally in an actual model.

In studying team-level knowledge exchange, one frequent approach that is taken is to document informational diversity at the team level along with team efforts to integrate such knowledge, with researchers then measuring the effect of these factors on team indicators such as perceived and 
actual performance, conflict and morale (e.g., Jehn, Northcraft, \& Neale, 1999). In a rare study combining research on analogical reasoning with team-level conflict, Paletz, Schunn, and Kim (2013) found that within-domain analogies in multidisciplinary teams preceded science and workprocess conflicts, with such conflicts perhaps being sparked because of knowledge gaps between team members with disparate backgrounds.

\section{Hypotheses}

Combining the two literatures that we have reviewed, which are concerned respectively with analogical reasoning and with knowledge sharing, we aimed to test a series of derived hypotheses on how variations in source domain knowledge may lead to differences in analogical retrieval and mapping. Specifically, we aimed to test whether a match between educational domain knowledge and the domain of the source analogy is predictive of analogy retrieval as well as differences in analogy extension and levels of uncertainty. Given that background knowledge relating to the source domain should render the source domain more accessible in memory (cf. the POLR model), we predicted that:

$\mathrm{H}_{1}$ : Analogy sources that match an individuals' educational background domains should be more frequent than would be expected by chance.

Upon the generation of an analogy from a specific source, we further predicted that analogy sources matching individuals' educational background domains would be distinct in terms of their duration, number of revisits and level of uncertainty compared to analogy sources that mismatched individuals' educational background domains. More specifically:

$\mathrm{H}_{2}$ : Analogy sources that match versus mismatch individuals' educational background domains should increase the duration of the team dialogue focused on the analogy. 
$\mathrm{H}_{3}$ : Analogy sources that match versus mismatch individuals' educational background domains should increase the number of times the analogy is revisited in the team dialogue.

$\mathrm{H}_{4}$ : Analogy sources that match versus mismatch individuals' educational background domains should decrease the level of expressed epistemic uncertainty in the team dialogue.

The dependent variables associated with $\mathrm{H}_{2-4}$ were not only examined in terms of the key predictor variable of whether analogy sources matched versus mismatched individuals' educational background domains, but were also examined in terms of the predictor variables of analogical distance and analogical function, as discussed in Section 1.1. The effects of analogical distance and analogical function were examined in order to determine whether these alternative variables would provide a better explanatory account of variation in the dependent variables than whether analogy sources matched versus mismatched educational background domains. Based on past research (Ball \& Christensen, 2009; Christensen \& Schunn, 2007), for $\mathrm{H}_{2-3}$ we predicted that analogy duration and analogy revisits would increase with problem solving analogies compared to other analogy types (i.e., analogies used for the purpose of problem finding, explaining or function finding).

\section{Methods}

The present analysis involved examining the set of verbal transcripts arising from a study of team design thinking that took place within a leading greeting card company. The verbalizations had been collected over a five-day intensive workshop involving a diverse set of seven university students working on solving a complex design challenge: "to create innovative new concepts from existing archival resources of a greeting card company for products and/or services in new or unique formats (i.e., 3-D and/or emerging media) that enhance the way people under 30 years of 
age relate to one another to celebrate birthdays and create stronger connections" (see D'souza, this issue, for further details of the project background, design brief and collaborative environment). The students solved the challenge in close collaboration through team discussions during which they were constantly talking aloud, thereby providing a rich, ongoing, external record of their thinking and reasoning. No special instructions to think-aloud were given.

The students were selected for their diversity in terms of their academic specialization and skill-set. Although at the same mid-western university in the US, they were selected from different departments (i.e., Art, Architectural Studies, English, Psychology, and Journalism), possessed distinct skills (i.e., drawing and painting, interior design, photography, folklore and digital storytelling, graphic design, digital archives, and print journalism) and had different levels of academic standing (5 undergraduate students, 1 graduate masters student and 1 graduate $\mathrm{PhD}$ student). None of the team members were familiar with each other before the project started.

The data had been collected using video, audio, and screen/display recordings in a lab setting over the five-day duration of the study. For the present analysis the verbalizations were transcribed and coded using the 'in vivo methodology' (Christensen \& Ball, 2014), which entails subjecting ethnographically collected recordings to procedures that are associated with formal protocol analysis (e.g., Ericsson \& Simon, 1993). The recordings were transcribed and segmented according to turn-taking during conversation. Transcriptions from the full five days were used in the present data analysis and covered more than $14 \mathrm{~h}$ of video, yielding a total of 2228 data segments.

\subsection{Protocol coding}

Initial design-problem presentations and the feedback session on Day 5 were removed from the dataset along with segments containing only contextual information written by the data collectors 
(and thus not containing verbal data). This data-reduction removed a total of 418 segments, leaving 1810 segments in the final, reduced dataset.

A code for epistemic uncertainty was added to each data segment in order to estimate the degree of this uncertainty in the design dialogue. Epistemic uncertainty was coded by the first author using a syntactic approach (Christensen \& Schunn, 2009; Trickett, Trafton, Saner, \& Schunn, 2007; Chan et al., 2012), whereby 'hedge words' that are linked to epistemic uncertainty were located, such as 'maybe', possibly', 'guess', 'don't know', 'believe' and so on. Then, for each hedge word, a qualitative screening was carried out to ensure that the hedge word, used in that context, did in fact display epistemic uncertainty (e.g., as opposed to being a politeness marker). All segments were coded for epistemic uncertainty using a binary scheme, that is, low (two or fewer uncertainty hedge words present in a segment) versus high (more than two uncertainty hedge words present in a segment).

Next, the transcripts were coded for analogizing by two independent coders who had received training in protocol analysis. All segments were coded for analogizing using the method developed by Dunbar $(1995,1997)$ and previously applied in design contexts (e.g., Ball \& Christensen, 2009; Chan \& Schunn, 2015, 2007; Wiltschnig, Christensen, \& Ball, 2013). A segment was coded as involving an analogy when a designer referred to another source of knowledge to explain, create, modify or evaluate a current design.

All analogies identified in the transcripts were then subjected to coding for analogical distance by applying a binary categorization scheme to capture within-domain analogies (where mappings were from sources that belonged to the same domain as the target problem) and between-domain analogies (where mappings were from sources that were remote to the target domain). Analogies were further coded for analogical purpose in reference to the analogy's 'function' or 'goal'. The 
code for analogical purpose involved Ball and Christensen's (2009) scheme (cf. Christensen \& Schunn, 2007), which included four categories: problem identification (noticing a possible problem in the design, where the problem was taken from an analogous source domain); function finding (mapping new functions to the design via analogy); explanation (considering a concept retrieved from a source domain to explain an aspect of the target domain); and solution generation (transferring potential solution concepts from a source to the target domain).

All analogies were additionally coded for whether the source analogy matched the domain background of the speaker. A coding scheme was developed listing the educational domain backgrounds of the seven participants, with the addition of an eighth category labelled 'other'. The code for each background domain was developed through information derived from the educational programmes the individuals participated in, supplemented with information concerning knowledge and interests uttered verbally within the videos. Each analogy was then coded blind to the person speaking in the transcript for the closest match between the analogy source and one of these background knowledge domains. When the background of the person initiating an analogy matched the domain of the analogy source, the analogy was coded as a 'match' as opposed to a 'mismatch'.

The analogies were finally classified using a binary categorization scheme on the following dimensions: (1) analogy length, that is, short (involving just one segment) versus long (involving more than one segment); and (2) analogy revisits, that is, whether the analogy was revisited later on in the transcript at least once versus not at all.

\subsection{Inter-coder reliability checks}

For the analogy codes, two independent coders each coded a subset of the transcripts comprising 131 segments (i.e., about $7 \%$ of the transcribed dataset - or 40 min of video). The coders had received general training in the analysis of design transcripts and were also given some 
familiarization and practice with the present coding categories. Reliability was calculated using Cohen's kappa, yielding the following satisfactory coefficients: analogy present $(\kappa=.70)$; analogical distance $(\kappa=.75)$; analogical function $(\kappa=.69)$; and analogical match to educational background domain $(\kappa=.77)$. Analogical length and revisits were based on automatic tabulations, and were thus not subjected to inter-coder reliability checks. The epistemic uncertainty code is primarily syntax-based (although a second qualitative screening step is added), and for that reason epistemic uncertainty was not subjected to reliability analysis. Previous reliability checks for epistemic uncertainty have yielded very high reliability, typically in the range of $\kappa=.88$ to .95 .

\section{Results}

\subsection{Descriptive data}

A total of 205 analogy segments were identified as making up 101 distinct analogies (11\% of the dataset thus contained analogies). The length of analogies ranged from 1 to 14 segments per analogy (mean $=2.0$ segments). For the purpose of the analysis, analogy length was coded in a binary manner as either short (1 segment; $62 \%$ of analogies) or long (more than one segment).

Of the analogies, $14 \%$ were revisited at a later stage in the transcript, while the rest were not revisited and were only mentioned once. In terms of distance, $52 \%$ of analogies were withindomain, whereas in terms of function, $3 \%$ served the purpose of problem finding, $17 \%$ were problem-solving analogies, $73 \%$ served the purpose of explaining to other team members, and $6 \%$ were function-finding analogies. Due to the low number of problem-finding and function-finding analogies, these categories were excluded from subsequent regression analysis. In relation to the match to the individuals' educational background domain, $26 \%$ of analogies were matched to the domain knowledge of the person initiating the analogy. 
In the dataset, each segment contained on average 0.55 hedge words that were indicative of epistemic uncertainty. For the purpose of the analysis, uncertainty was coded in a binary manner as either high (more than two uncertainty hedge words in a segment; $9 \%$ of data segments; $42 \%$ of analogy segments) or low (two or fewer uncertainty hedge words in a segment).

The students differed in terms of how many analogies they proposed (from 3 to 44 unique analogies proposed) and how many analogy segments they participated in dialogue on (from 4 to 88 segments of analogizing). When benchmarked against the number of segments verbalized by each student, the number of unique analogies proposed (from $4 \%$ to $11 \%$ of each participant's segments) did not differ significantly between participants, $\chi^{2}(6)=11.12$ (not significant). However, the participants did differ significantly in the number of analogy segments that they participated in dialogue on (from $8 \%$ to $19 \%$ of each participant's segments), although the effect was quite small, $\chi^{2}(6)=$ $15.55, p<.02$, Cramer's V $=.038$.

\subsection{Proportion of analogies with a match to educational background domain}

To test whether the proportion of analogies with a match to the background domain exceeded what was expected in the dataset according to chance $\left(\mathrm{H}_{1}\right)$, we conducted a one sample t-test that compared the mean match $(M=0.26)$ to the hypothetical expected level of 0.14 (i.e., $1 / 7)$, given that 7 people participated in the group. This t-test revealed a significant effect, $t(101)=2.62, p<$ .02 . The $1 / 7$ baseline was chosen conservatively even though the coding contained 8 categories, where the eighth category of 'other' contained multiple domains, at least in principle. In sum, this finding supports the hypothesis $\left(\mathrm{H}_{1}\right)$ that the person proposing an analogy is more likely to be drawing on a source from their own educational background domain compared to chance. 
We extended the latter analysis so that it covered all of the individuals participating in particular episodes of analogical reasoning, irrespective of whether or not they had initiated the analogy. We conducted the same form of one-sample t-test as previously, with the mean match to educational background domain recalculated accordingly (i.e., $\mathrm{M}=0.23$ ). This test was again reliable, $t(204)=$ $3.08, \mathrm{p}<.003$, indicating that significantly more participants with an educational background domain matching the source domain participated throughout the analogical reasoning process regardless of having initiated the analogy, compared to what would be expected by chance.

\subsection{Analogy length}

To examine whether analogy length (short versus long) differed in terms of analogical distance, analogical function and match to the educational background domain of the person proposing the analogy $\left(\mathrm{H}_{2}\right)$, we applied stepwise (Wald backwards) binary logistic regression analyses. The predictor variables were therefore the categorical variables analogical distance (within domain vs. between domain), analogical function (problem solving vs. explaining) and match to educational background domain (match vs. mismatch).

The stepwise regression left one variable in the final equation (match to educational background domain). An evaluation of the final model versus a model with intercept only was, however, a small margin short of statistical significance, $\chi^{2}(1, \mathrm{~N}=91)=2.82, p=.09$. Nevertheless, the model was able to classify correctly with an overall success rate of $64 \%$. Table 1 shows the logistic regression coefficient, Wald test, and odds ratio for the final predictor. The odds ratio indicates that a long analogy compared to a short analogy is 2.3 times more likely (i.e., 1/0.44) to contain a source match to the background domain of the person proposing the analogy, although, as noted, this effect did not quite reach significance. This finding therefore presents some qualified support for $\mathrm{H}_{2}$. 
Table 1. Logistic regression (final model) predicting analogy length (short vs. long) from analogical distance, analogical function, and match to educational background domain

\begin{tabular}{llllllll}
\hline & B & SE & Wald & df & Sig & Exp(B) \\
\hline \multirow{2}{*}{ Step 3 } & Match to educational & -.83 & .491 & 2.82 & 1 & .09 & .44 \\
& background domain & & & & & & \\
& Constant & .09 & 0.42 & 0.04 & 1 & .84 & 1.09 \\
\hline
\end{tabular}

\subsection{Analogy revisits}

A binary logistic regression model was constructed with the outcome variable being analogy revisits, with the model otherwise being identical to that constructed for analogy length. The stepwise regression left one variable in the final equation (match to educational background domain). An evaluation of the final model versus a model with intercept only was statistically significant, $\chi^{2}(1, \mathrm{~N}=91)=5.79, p<.02$. The model was able to classify correctly with an overall success rate of $86 \%$ (see Table 2). The odds ratio indicates that an analogy that was part of the conversation only once compared to one that was revisited later is 4.5 times less likely (i.e., 1/0.22) to contain a source match to the background domain of the person proposing the analogy. This result provides clear support for $\mathrm{H}_{3}$. 
Table 2. Logistic regression (final model) predicting analogy revisits (no revisit vs. revisit) from analogical distance, analogical function, and match to educational background domain

\begin{tabular}{llllllll}
\hline & B & SE & Wald & df & Sig & Exp(B) \\
\hline \multirow{2}{*}{ Step 3} & Match to educational & -1.51 & .62 & 5.86 & 1 & .02 & .22 \\
& background domain & & & & & & \\
& Constant & -.83 & .45 & 3.33 & 1 & .07 & .44 \\
\hline
\end{tabular}

\subsection{Epistemic uncertainty in analogies}

More analogy-related transcript segments were of high uncertainty (39\%) compared to transcript segments that were unrelated to analogies $(6 \%), \chi^{2}(1)=132.15, p<.001$, indicating that analogies were linked to high degrees of epistemic uncertainty. A binary logistic regression model was constructed with the outcome variable being epistemic uncertainty in analogy segments (low vs. high), but otherwise identical to the models previously described. The stepwise regression left one variable in the final equation (match to background domain). An evaluation of the final model versus a model with intercept only was statistically significant, $\chi^{2}(1, \mathrm{~N}=91)=4.58, p<.04$. The model was able to classify correctly with an overall success rate of $64 \%$ (see Table 3 ). The odds ratio indicates that an analogy high in epistemic uncertainty compared to one low in epistemic uncertainty is 2.86 times more likely (i.e., 1/0.35) to contain a source match to the background domain of the person proposing the analogy. This was significant, but was directionally counter to the proposed hypothesis $\left(\mathrm{H}_{4}\right)$, which predicted that analogies that match individuals' educational background domains should be associated with decreased (rather than increased) levels of expressed epistemic uncertainty in the team dialogue. 
Table 3. Logistic regression (final model) predicting epistemic uncertainty (low vs. high) in analogy segments from analogical distance, analogical function, and match to educational background domain

\begin{tabular}{llcccccc}
\hline & & B & SE & Wald & df & Sig & $\operatorname{Exp(B)}$ \\
\hline \multirow{2}{*}{ Step 3 } & Match to educational & -1.05 & .50 & 4.45 & 1 & .04 & .35 \\
& background domain & & & & & & \\
& Constant & .44 & .42 & 1.07 & 1 & .30 & 1.56 \\
\hline
\end{tabular}

\section{Discussion}

The present research represents an attempt to draw together two hitherto distinct research traditions, one focusing on analogical reasoning and the other focusing on knowledge sharing. The analogical reasoning tradition has customarily employed experimental methods that hold background knowledge constant in design contexts, either by making use of homogeneous design participants with very similar educational experiences and training (e.g., Ball et al., 2004; Christensen \& Schunn, 2007; Jagodzinski et al., 2000) or else by presenting source analogies and design exemplars that are equally accessible to each participant (e.g., Casakin, 2004; Casakin \& Goldschmidt, 1999; Goldschmidt, 1995). These methodologies obviate the analysis of individual differences in background domain knowledge as a source of variation in analogy retrieval and application. In contrast, the knowledge-sharing literature embraces such individual differences in the background domain knowledge of members of heterogeneous teams so as to examine how this source of variation translates into outcomes associated with team performance such as creativity and innovation (e.g., Cummings, 2004; Jackson et al., 2006; Jehn et al., 1999; Pulakos et al., 2003; Wang \& Noe, 2010). However, the knowledge-sharing methodology fails to establish directly the 
role of analogizing in fueling innovation, despite assuming that analogy is likely to be a key element of the creative potential of such heterogeneous teams (e.g., Nonaka, 1991, 1994).

Our analysis of the present dataset afforded a unique opportunity to combine these disparate research traditions in order to examine directly the nature, role and consequences of analogy use in a heterogeneous design team in which team members were undertaking extensive knowledge sharing. The study that gave rise to the dataset was run as a five-day workshop and comprised a quasi-experimental set-up involving seven students with distinct backgrounds and experiences collaboratively tackling a complex, company-based design problem. The dataset therefore allowed us to address head-on various issues relating to the retrieval of analogies by different team members and the way in which these analogies matched or mismatched individuals' educational background domains. In addition, we were able to drill down further so as to examine whether analogies that matched versus mismatched individuals' educational background domains showed distinctive characteristics in terms of their length (i.e., duration), the frequency with which they were revisited in the ongoing team dialogue and their level of uncertainty. Our analysis of the dataset aimed to address a series of a priori hypotheses concerning the relation between domain background knowledge and analogical reasoning in heterogeneous design teams, with a majority of these hypotheses finding good levels of statistical support.

The first hypothesis that we tested $\left(\mathrm{H}_{1}\right)$ was that analogies matching individuals' educational background domains should be more frequent than would be expected by chance because of the greater accessibility of such analogies (e.g., as predicted by the 'path-of-least-resistance' model of the creative imagination; see Ward, 1994, 1995, 1998). The results supported $\mathrm{H}_{1}$ and revealed that when proposing an analogy the designer was more likely to draw on a source from their own educational background domain compared to chance. Further analyses indicated that when a 
designer's background domain matched the source domain of the analogy they were also more likely to participate in the analogy episode irrespective of whether they had actually generated the analogy in the first place. This effect presumably arises once again because of domain familiarity and information accessibility or availability (e.g., Reber, 2004).

In relation to $\mathrm{H}_{1}$ we note that the effect, although reliable, was of relatively small magnitude in the present dataset. This modest effect may be a consequence of the presence of an inherent constraint in the present design task, which was the requirement for the team to come up with a 'web-based solution'. This requirement may have promoted the availability of a secondary domain of source analogies that were well-known to all of the workshop participants: that of web-based services. All of the participants would have been intimately familiar with a host of more common social network and e-services sites (as was corroborated by the frequency of their being mentioned in the transcripts) and this may have provided them with a domain containing paths of even less resistance compared to their educational background domain. Future studies will be valuable to ascertain whether the effect of retrieving from educational background domains is of greater magnitude in other design contexts.

Our second and third hypotheses were that analogies that match versus mismatch individuals' educational background domains should increase the duration of the team dialogue focused on the analogy $\left(\mathrm{H}_{2}\right)$ and should also increase the number of analogy revisits $\left(\mathrm{H}_{3}\right)$. These effects were again predicated on assumptions relating to the greater availability of more extensive and elaborate knowledge from educational background domains. The duration effect $\left(\mathrm{H}_{2}\right)$ was marginally significant, whereas the re-visitation effect $\left(\mathrm{H}_{3}\right)$ was highly reliable. These effects indicate that participants spent slightly longer thinking about the analogies from their background domains and returned to these analogies significantly more frequently during the design dialogue, presumably 
because their richer knowledge of the source domains enabled a more elaborate analogical reasoning process. The partial support obtained for $\mathrm{H}_{2}$ and the full support for $\mathrm{H}_{3}$ underscore the importance of designers drawing on their unique background domain knowledge when generating analogies that can facilitate solution transfer into a new domain.

Finally, our fourth hypothesis $\left(\mathrm{H}_{4}\right)$ was that analogies that match versus mismatch individuals' educational background domains should be associated with a decreased level of expressed epistemic uncertainty in the team dialogue. Counter to $\mathrm{H}_{4}$, however, we observed the opposite effect in that the analogies that matched versus mismatched educational background domains were associated with an increased level of expressed uncertainty. One possible explanation for this unexpected effect is that experienced uncertainty in the context of conversations relating to analogies might be inferred by designers from their own past experience. In other words - and counter to the arguments presented in the introduction - perhaps increased domain experience translated into more knowledge of all the contingencies involved in transferring knowledge from one domain to another. As such, a person with more domain knowledge would express more uncertainty when drawing an analogy from their expert domain given that they know from experience that such analogical mappings are less straightforward than one might otherwise believe. A designer with less experience in the source domain may (erroneously) believe that the transfer will probably be straightforward. This account would suggest that when it comes to extending knowledge across boundaries, greater experience of a source domain will lead to higher perceived and expressed uncertainty when compared to less experience of a source domain. It would be valuable for future research to corroborate this effect given its important theoretical implications for understanding the links between domain expertise and epistemic uncertainty in design-by-analogy and in analogical problem solving more generally. 
We finally note that our detailed statistical examination of $\mathrm{H}_{2}, \mathrm{H}_{3}$ and $\mathrm{H}_{4}$ in terms of the roles of analogical distance and analogical function as determinants of variation in our dependent measures demonstrated that neither of these factors had any reliable impact on analogy length, analogy revisits or expressed epistemic uncertainty. The lack of any effects in relation to these predictors is contrary to what we expected, since previous research on analogizing in design (e.g., Ball \& Christensen, 2009; Christensen \& Schunn, 2007) has indicated that analogy duration and analogy revisits should increase with problem solving analogies compared to other analogy types (i.e., analogies used for problem finding, explaining or function finding). It would appear that in the present design context it is the heterogeneous make-up of the design team that dominates any effects arising in the dependent variables of analogy duration, analogy revisits or expressed epistemic uncertainty, confirming that team heterogeneity is a very potent force in design-byanalogy. Indeed, if it is assumed that analogizing serves a major role in driving creativity then the present dataset attests to the power of team heterogeneity for enhancing design innovation.

\subsection{Future directions}

In terms of future directions for research on analogizing in heterogeneous design teams, we have already noted the importance of replicating what was perhaps the most surprising finding in the present analysis, which was that the analogies that matched versus mismatched educational background domains were associated with an increased level of expressed uncertainty, whereas we had expected that the opposite would be the case. In addition, it would be interesting for future research utilising the present dataset to code analogies in terms of their level of abstraction along a continuum extending from the very detailed to the highly abstract. This kind of coding approach was adopted by Ball et al. (2004) in a study comparing the spontaneous analogising of experts and novices in an engineering design context. They coded analogies dichotomously as being either 
“case-driven" (i.e., relating to concrete prior design problems whose detailed solution elements could be mapped onto a current problem) or "schema-driven" (i.e., relating to abstract experiential knowledge of a familiar type of design problem and its solution). Ball et al.'s analysis revealed that expert designers demonstrated more schema-driven than case-driven analogizing, whilst novice designers showed the reverse pattern. Given that the present design team involved novice designers it would be predicted that their generated analogies would arise primarily at a concrete level rather than at a more abstract, schema-based level, although this remains an empirical question. Some highly suggestive evidence, however, derives from the analysis of the same dataset reported by Kokotovich and Dorst (this issue), which showed that the reasoning of the design team rarely progressed far from concrete levels of detail and never progressed to the highly abstract levels that are typically associated with 'expert', 'master' or visionary' designers. Although Kokotovich and Dorst did not specifically examine analogizing - focusing instead on design reasoning in general the way in which such reasoning was seen to be limited to fairly concrete levels of detail suggests that any analogy production was likewise occurring at this concrete level.

Another analysis of the present dataset (D'souza \& Dastmalchi, this issue) also examined some similar issues to Kokotovich and Dorst concerning the role of abstraction in design creativity. D’souza and Dastmalchi's investigation focused specifically on the dynamics of creative idea production, with aspects of their analysis examining key creativity indicators such as occurrences of 'concept synthesis'. The authors followed Nagai and Taura (2006; see also Nagai, Taura, \& Mukai, 2009) in identifying three different ways of achieving concept synthesis in the creative process, with each way moving higher up the abstraction hierarchy, that is: (1) concept abstraction, which is the identification and mapping of similar, concrete features or properties between two concepts to create a novel concept (equivalent to analogizing at a very literal level); (2) concept blending, which is the identification of both similarity and dissimilarity between concepts with a view to creating a 
novel synthesis capitalizing on both the correspondence and discrepancy; and (3) concept integration, which is the identification of thematic relations to create a novel synthesis that exploits highly abstract relations. Interestingly, D'souza and Dastmalchi's analysis revealed that it was the latter, more abstract activity of concept integration that showed the greatest variability in its frequency as a function of the education background and specialist expertise of team members. More specifically, the team member from the English discipline (with storytelling skills) contributed the most to concept integration whilst the psychology and journalism team members (with skills in digital archives and print journalism, respectively) made almost no contribution to concept integration - or indeed to any other aspect of concept synthesis.

D'souza and Dastmalchi's findings reveal that even though relatively novice design reasoners may typically be unable not reach the more rarified heights of abstraction that characterize true expertise (cf. Kokotovich \& Dorst, this issue), it is nevertheless the case that certain team members with particular educational backgrounds and specialist expertise can at least sometimes fuel creative idea generation at a somewhat higher level of abstraction than a purely concrete level of literal similarity between objects or concepts. In this respect it is also possible for abstract analogical reasoning, even in novice designers, to derive occasionally from team members with particular backgrounds and skills. Again, analysing the present dataset specifically with an eye to the level of abstraction of the generated analogies could be very informative on these issues. Furthermore, it would be useful to explore such factors not only in terms of the background education and expertise of team members, but also in terms of personality characteristics and processing styles, such as the tendency for some designers to share their ideas orally, whilst others prefer to reflect their thoughts privately in their journals. 
In relation to the analysis of the present dataset by Cardoso, Badke-Schaub, and Eriş (this issue), we were fascinated by their observation that 'high-level' question-asking in the form of deep reasoning questions (e.g., asking for causal explanations) or generative design questions (e.g., asking about alternative solution avenues or methods) appeared to play such a crucial role in triggering an 'inflection moment' in the general direction that the team was following. Cardoso et al. propose that such moments are associated with insightful 'problem reframing' and the subsequent generation of creative solution ideas. What is perhaps most intriguing about this observation is that these inflection moments or turning points appeared to be preceded by what Cardoso et al. refer to as a 'mood of dissatisfaction', which ultimately culminates in the formulation of a high-level question that thence promotes the problem reframing. These observations lead us to speculate that the socalled mood of dissatisfaction may well be correlated with expressions of epistemic uncertainty (since it is likely that dissatisfaction will be associated with the generation of hedge words like 'maybe' and 'perhaps'). Furthermore, such dissatisfaction may, in turn, be linked to creative analogy generation as part of the problem reframing and creative idea generation process - again potentially bringing analogizing to centre stage.

These latter issues would be well worth exploring in the present dataset as well as in other design datasets, especially given the potential to link together various hitherto disparate concepts such as those of epistemic uncertainty, design dissatisfaction, analogizing, turning points and reframing. Such an analysis may also connect in interesting ways with the concept of problem-solution coevolution in creative design (cf. Wiltschnig et al., 2013) and with notions such as 'inspiration' and 'illumination' in the design process (cf. Chandrasekera, Vo, \& D'souza, 2013), which may be closely correlated with analogy-based creative leaps. 


\subsection{Conclusion}

To conclude, the main contribution of the present study is that it represents what we believe is the first exploration of the impact of educationally-derived background knowledge on team analogizing in a heterogeneous design team. Given the limitations arising from the use of a single-case dataset, however, we concede that the present findings need to be corroborated by analysing other realworld design datasets. Ideally, too, the findings need to be replicated by means of testing larger samples in more controlled experimental settings. Nonetheless, we suggest that our findings provide some good support for claims deriving from the knowledge-sharing literature regarding the existence of a cognitive route that leads from knowledge diversity through analogical reasoning to the production of creative design ideas. 


\section{References}

Antonietti, A., \& Gioletta, M. A. (1995). Individual differences in analogical problem solving. Personality \& Individual Differences, 18, 611-619.

Argote, L. (1999). Organizational Learning: Creating, Retaining and Transferring Knowledge. Norwell, MA: Kluwe.

Ball, L. J., Lambell, N. J., Reed, S. E., \& Reid, F. J. M. (2001). The exploration of solution options in design: A 'Naturalistic Decision Making' perspective. In P. Lloyd, \& H. Christiaans (Eds.), Designing in Context (pp. 79-93). Delft, The Netherlands: Delft University Press.

Ball, L. J., Ormerod, T. C., \& Morley, N. J. (2004). Spontaneous analogising in engineering design: A comparative analysis of experts and novices. Design Studies, 25, 495-508

Ball, L. J., \& Christensen, B. T. (2009). Analogical reasoning and mental simulation in design: Two strategies linked to uncertainty resolution. Design Studies, 30, 169-186.

Bearman, C. R., Ball, L. J., \& Ormerod, T. C. (2007). The structure and function of spontaneous analogising in domain-based problem solving. Thinking \& Reasoning, 13, 273-294.

Cardoso, C., \& Badke-Schaub, P., \& Eriş, O. (this issue). Inflection moments in the design discourse: How questions drive problem framing during idea generation. Design Studies.

Casakin, H. (2004). Visual analogy as a cognitive strategy in the design process: Expert versus novice performance. Journal of Design Research, 4, No 2.

Casakin, H., Ball, L. J., Christensen, B. T., \& Badke-Schaub, P. G. (2015). How do analogizing and mental simulation influence team dynamics in innovative product design? Artificial Intelligence for Engineering Design, Analysis \& Manufacturing, 29, 173-183.

Casakin, H., \& Goldschmidt, G. (1999). Expertise and the visual use of analogy: Implications for design education. Design Studies, 20, 153-175.

Chan, J., \& Schunn, C. D. (2015). The impact of analogies on creative concept generation: Lessons from an in vivo study in engineering design. Cognitive Science, 39, 126-155.

Chan, J., Dow, S. P., \& Schunn, C. D. (2015). Do the best design ideas (really) come from conceptually distant sources of inspiration? Design Studies, 36, 31-58.

Chan, J., Paletz, S., \& Schunn, C. D. (2012). Analogy as a strategy for supporting complex problem solving under uncertainty. Memory \& Cognition, 40, 1352-1365.

Chandrasekera, T., Vo, N., \& D'souza, N. (2013). The effect of subliminal suggestions on Sudden Moments of Inspiration (SMI) in the design process. Design Studies, 34, 193-215.

Christensen, B. T. (2010). Images of users and products shown during product design increase users' willingness-to-use the innovation. Artificial Intelligence for Engineering Design, Analysis \& Manufacturing, 24, 179-189. 
Christensen, B. T., \& Ball, L. J. (2014). Studying design cognition in the real world using the 'in vivo' methodology. In P. Rodgers, \& J. Yee (Eds.), The Routledge Companion to Design Research (pp. 317-328). Abingdon, UK: Routledge.

Christensen, B. T., \& Schunn, C. D. (2007). The relationship of analogical distance to analogical function and pre-inventive structure: The case of engineering design. Memory \& Cognition, 35, 2938.

Christensen, B. T., \& Schunn, C. D. (2009a). Putting blinkers on a blind man. Providing cognitive support for creative processes with environmental cues. In A. B. Markman, \& K. L. Wood (Eds.), Tools for Innovation (pp. 48-74). Oxford, UK: Oxford University Press.

Christensen, B. T., \& Schunn, C. D. (2009b). The role and impact of mental simulation in design. Applied Cognitive Psychology, 23, 327-344.

Christiaans, H., \& Andel, J. (1993). The effects of examples on the use of knowledge in a student design activity: The case of the 'flying Dutchman'. Design Studies, 14, 58-74.

Corkill, A. J., \& Fager, J. J. (1995). Individual differences in transfer via analogy. Learning \& Individual Differences, 7, 163-187.

Cross, N. (2006). Designerly Ways of Knowing. London: Springer.

Cummings, J. N. (2004). Work groups, structural diversity, and knowledge sharing in a global organization. Management Science, 50, 352-364.

Dahl, D. W., \& Moreau, P. (2002). The influence and value of analogical thinking during new product ideation. Journal of Marketing Research, 39, 47-60.

D'souza, N. (this issue). Investigating design thinking of a complex multidisciplinary design team in a new media context. Design Studies.

D'souza, N., \& Dastmalchi, M. R. (this issue). Creativity on the move: Exploring little-c (p) and big-C (p) creative events within a multidisciplinary design team process. Design Studies.

Dunbar, K. (1995). How scientists really reason: Scientific reasoning in real-world laboratories. In R. J. Sternberg, \& J. E. Davidson (Eds.), The Nature of Insight (pp. 365-395). Cambridge, MA: MIT Press.

Dunbar, K. (1997). How scientists think: On-line creativity and conceptual change in science. In T. B. Ward, S. M. Smith, \& J. Vaid (Eds.), Creative Thought: An Investigation of Conceptual Structures and Processes (pp. 461-493). Washington, DC: American Psychological Association.

Ericsson, K. A., \& Simon, H. A. (1993). Protocol Analysis: Verbal Reports as Data (Revised Edition). Cambridge, MA: Bradford Books.

Gentner, D., \& Stevens, A. L. (Eds). (1983). Mental Models. Hillsdale, NJ: Lawrence Erlbaum Associates, Inc. 
Gick, M. L., \& Holyoak, K. J. (1980). Analogical problem solving. Cognitive Psychology, 12, 306355.

Goldschmidt, G. (1995). Visual displays for design: Imagery, analogy and databases of visual images. In A. Koutamanis, H. Timmermans, \& I. Vermeulen (Eds.), Visual Databases in Architecture (pp. 53-74). Aldershot, UK: Avebury.

Gupta, A. K., \& Govindarajan, V. (2000). Knowledge management's social dimension: Lessons from Nucor Steel. Sloan Management Review, 42, 71-80.

Helms, M., Vattam, S. S., \& Goel, A. K. (2009). Biologically inspired design: Process and products. Design Studies, 30, 606-622.

Holyoak, K. J., \& Koh, K. (1987). Surface and structural similarity in analogical transfer. Memory \& Cognition, 15, 332-340.

Holyoak, K. J., \& Thagard, P. (1997). The analogical mind. American Psychologist, 52, 35.

Jackson, S. E., Chuang, C. -H., Harden, E. E., \& Jiang, Y. (2006). Toward developing human resource management systems for knowledge-intensive teamwork. Research in Personnel \& Human Resources Management, 25, 27-70.

Jagodzinski, P., Reid, F. J. M., Culverhouse, P., Parsons, R., \& Phillips, I. (2000). A study of electronics engineering design teams. Design Studies, 21, 375-402.

Jansson, D. G., \& Smith, S. M. (1991). Design fixation. Design Studies, 12, 3-11.

Jehn, K. A., Northcraft, G. B., \& Neale, M. A. (1999). Why differences make a difference: A field study of diversity, conflict and performance in workgroups. Administrative Science Quarterly, 44, 741-763.

Kokotovich, V., \& Dorst. K. (this issue). The art of 'stepping back: Studying levels of abstraction in a diverse design team. Design Studies.

Moreno, D. P., Hernandez, A. A., Yang, M. C., Otto, K. N., Hölttä-Otto, K., Linsey, J. S., Wood, K. L., \& Linden, A. (2014). Fundamental studies in design-by-analogy: A focus on domain-knowledge experts and applications to transactional design problems. Design Studies, 35, 232-272.

Nagai, Y., \& Taura, T. (2006). Formal description of concept-synthesizing process for creative design. In J. S. Gero (Ed.), Design Computing and Cognition'06 (pp. 443-460). Dordrecht, Netherlands: Springer.

Nagai, Y., Taura, T., \& Mukai, F. (2009). Concept blending and dissimilarity: Factors for creative concept generation process. Design Studies, 30, 648-675.

Nonaka, I. (1991). The knowledge-creating company. Harvard Business Review, 69, 96-104.

Nonaka, I. (1994). A dynamic theory of organizational knowledge creation. Organization Science, 5, 14-37. 
Novick, L. R. (1988). Analogical transfer, problem similarity, and expertise. Journal of Experimental Psychology: Learning, Memory, \& Cognition, 14, 510-520.

Novick, L. R., \& Holyoak, K. J. (1991). Mathematical problem solving by analogy. Journal of Experimental Psychology: Learning, Memory, \& Cognition, 17, 398-415.

Paletz, S. B. F., Schunn, C. D., \& Kim, K. (2013). The interplay of conflict and analogy in multidisciplinary teams. Cognition, 126, 1-19.

Polanyi, M. (1966). The Tacit Dimension. London: Routledge Kegan Paul.

Pulakos, E. D., Dorsey, D. W., \& Borman, W. C. (2003). Hiring for knowledge-based competition. In S. E. Jackson, M. A. Hitt, \& A.S. Denisi (Eds.), Managing Knowledge for Sustained Competitive Advantage: Designing Strategies for Effective Human Resource Management (pp. 155-176). San Francisco, CA: Jossey-Bass.

Reber, R. (2004). Availability. In R. Pohl (Ed.), Cognitive Illusions: A Handbook on Fallacies and Biases in Thinking, Judgement and Memory (pp. 147-164). Hove, UK: Psychology Press.

Trickett, S. B., Trafton, J. G., Saner, L. D., \& Schunn, C. D. (2007). "I don't know what is going on there": The use of spatial transformations to deal with and resolve uncertainty in complex visualizations. In M. C. Lovett \& P. Shah (Eds.), Thinking with Data. Mahwah, NJ: Erlbaum.

Visser, W. (1996). Use of episodic knowledge and information in design problem solving. In N Cross, H. Christiaans. \& K. Dorst (Eds.), Analysing Design Activity (pp. 271-289). Chichester, UK: Wiley.

Ward, T. B. (1994). Structured imagination: The role of category structure in exemplar generation. Cognitive Psychology, 27, 1-40.

Ward, T. B. (1995). What's old about new ideas? In S. M. Smith, T. B. Ward, \& R. A. Finke (Eds.), The Creative Cognition Approach (pp. 157-178). Cambridge, MA: MIT Press.

Ward, T. B. (1998). Analogical distance and purpose in creative thought: Mental leaps versus mental hops. In K. Holyoak, D. Gentner, \& B. Kokinov (Eds.), Advances in Analogy Research: Integration of Theory and Data from the Cognitive, Computational, and Neural Sciences (pp. 221230). Sofia, Bulgaria: New Bulgarian University Press.

Ward, T. B., Patterson, M. J., Sifonis, C. M., Dodds, R. A., \& Saunders, K. N. (2002). The role of graded category structure in imaginative thought. Memory \& Cognition, 30, 199-216.

Wiltschnig, S., Christensen, B. T., \& Ball, L. J. (2013). Collaborative problem-solution coevolution in creative design. Design Studies, 34, 515-542. 